\title{
A HISTÓRIA DA ESCOLA DE EDUCAÇÃO ESPECIAL BEM ME QUER - APAE DE TOLEDO - PARANÁ
}

\author{
Ireni Marilene Zago Figueiredo ${ }^{1}$ \\ Jackson Johann ${ }^{2}$
}

\section{RESUMO}

A APAE de Toledo - PR, fundada no ano de 1974, foi a primeira instituição criada para oferecer o atendimento educacional e social para as pessoas com deficiência no município. Sua instalação ocorreu devido ao empenho de lideranças comunitárias e pais de pessoas com deficiência, que sentiram a necessidade de ter na cidade uma entidade, instituição ou escola para atendimento especializado. Depois de 37 anos de serviços prestados a comunidade toledana, a APAE, que mantém a Escola Especial Bem Me Quer, se destaca como uma das instituições mais importantes na região Oeste do Paraná, oferecendo atendimento especializado para crianças com deficiência na Educação Infantil e no Ensino Fundamental, bem como para os jovens acima de 18 anos no Setor Profissionalizante. O artigo trata, portanto, do histórico da APAE de Toledo - PR, demonstrando que o Setor Profissionalizante foi instalado, em 1996, e reorganizado, em 1998, a partir do Processo de Educação Profissional e Colocação no Trabalho (PECT), com os programas de Iniciação Profissional, Qualificação Profissional e Colocação no Trabalho.

Palavras-chave: APAE - Toledo - PR. Educação Especial. Pessoa com Deficiência.

\section{THE HISTORY OF BEM ME QUER SPECIAL EDUCATION SCHOOL (APAE) OF TOLEDO - PARANÁ}

\begin{abstract}
The APAE (Association of Parents and Friends of Exceptional Persons) of Toledo-PR, founded in the year of 1974, was the first institution to be created in order to offer social and educational support to persons with disabilities within that municipality. Its settlement occurred due to the effort put into it by community leaders and parents of people with disabilities who felt the need for having an entity, institution or school in the city for specialized support. After 37 years providing services to the community of Toledo, the APAE, which holds the special education school Bem Me Quer, stands out as one of the most important institutions in West Paraná, by offering specialized support to children with disabilities in Infant Education and Basic Education, and also to young people over 18 years old in Vocational Education. In that sense, this article presents the history of the APAE of Toledo-PR, showing that the Vocational Sector was settled in 1996 and reorganized in 1998, based on the Process of Professional Education and Workplace Placement (PECT) with the programs of Professional Initiation, Professional Qualification and Workplace Placement.

Keywords: APAE - Toledo - PR. Special Education. Person with disability.
\end{abstract}


No ano de 1951 a cidade de Toledo $^{3}$ que ainda era distrito, foi desmembrada do município de Foz do Iguaçu. A posse do primeiro prefeito municipal e da primeira câmara de vereadores ocorreu em 14 de dezembro de 1952, data de comemoração do aniversário do município (SILVA, 1998, p. 110).

Com o crescimento da cidade surgiu, em 1958, a primeira instituição oficial de ensino no município, pois as escolas existentes até então eram mantidas por instituições religiosas ou pela Colonizadora Maripá S/A . "Era necessário que, tanto os agricultores, como também as demais pessoas que para cá vinham, aqui encontrassem escolas e assistência religiosa em andamento" (NIEDERAUER, 2004, p. 250). Dessa forma, a primeira escola mantida pelo governo estadual foi inaugurada na cidade de Toledo, em $1958^{5}$.

O processo de criação de uma instituição para garantir a assistência e a educação para os portadores de deficiência mental foi liderado pelo médico toledano Adolfo Dall Oglio ${ }^{6}$. A Associação de Pais e Amigos dos Excepcionais (APAE) de Toledo - PR foi fundada, portanto, em 1974 (SILVA, 1998, p. 285).

Durante a reunião para a sessão preparatória ficou acordado que "a entidade teria por meta e objetivo promover o bem estar, proteção e o ajustamento em geral dos indivíduos excepcionais, bem como, estimular os estudos e pesquisas relativos aos problemas dos excepcionais" (APAE de TOLEDO - Livro Ata, 1974, p. 7).

$\mathrm{Na}$ primeira reunião foi eleito o primeiro Conselho Deliberativo, bem como a primeira diretoria ${ }^{7}$ (APAE de TOLEDO - Livro Ata, 1974, p. 8). As atividades foram iniciadas no dia 08 de março de $1976^{8}$ (APAE de TOLEDO - Livro Ata, 1976, p. 9).

Em 1976 os funcionários ${ }^{9}$ da APAE escolheram, por meio de votação, o nome da instituição. Entre várias sugestões saiu vitorioso o nome Escola de Educação Especial Bem Me Quer, que passou a ser utilizado no início do ano letivo de 1977 (APAE de TOLEDO Livro Ata, 1976, p. 10).

Em 03 de maio de 1977 a Escola da APAE se submeteu a uma vistoria do Departamento de Educação Especial e teve parecer favorável para funcionamento da Secretaria de Educação e Cultura do Estado do Paraná. Assim sendo, no dia 02 de junho de 1977, a Escola Especial Bem Me Quer recebeu autorização oficial para funcionamento, através do Decreto Estadual no 3.528/1977, respeitando o Artigo 9º da Lei ${ }^{\circ}{ }^{\circ} 5.692$ de 11 de agosto de 1971. O Decreto Estadual foi assinado pelo Governador do Estado Jaime Canet Junior:

Art. 1 - É concedida, em caráter condicional e pelo prazo de dois anos, a partir do presente ano letivo, autorização para funcionamento da Escola Bem Me Quer, do município de Toledo, que manterá atendimento especializado à criança portadora de deficiência mental, tendo como entidade mantenedora a Associação de Pais e Amigos dos Excepcionais de Toledo.

Art. 2. A Escola autorizada a funcionar por esse decreto deverá observar no que lhe for aplicável, os preceitos da legislação estadual de ensino (PARANÁ, 1977, p. 1).

As primeiras diretrizes de um Plano Curricular para a educação da pessoa portadora de deficiência mental foram elaboradas seguindo as orientações da Lei $n^{\circ}$ 5.692/71. O Plano Curricular seguiu as orientações mínimas necessárias para orientar os professores como, por exemplo, o objetivo geral da educação da pessoa com deficiência, fundamentação filosófica, psicológica e sociológica, conteúdo programático das atividades Revista HISTEDBR On-line, Campinas, número especial, p. 100-110, mai2012 - ISSN: 1676-2584 101 
e as principais estratégias de ação do professor (APAE de TOLEDO - Livro Ata, 1977, p. 11).

Em 26 de abril de 1980, com trabalho e envolvimento de vários segmentos da sociedade toledana ${ }^{10}$, a APAE constrói a sede própria da escola ${ }^{11}$.

Em 1980, a APAE [de Toledo-PR] inaugura a sede própria da escola. Começa agora, uma nova etapa na história da educação infantil, fundamental e profissional. Até então, para a organização das salas e turmas não se tinha critério definido. $\mathrm{O}$ atendimento oferecido tinha como base um forçado aprendizado de escolaridade com predominância na escrita, considerando-se apenas, as habilidades motoras (treino visual/motor). Para o atendimento profissional, a ênfase dada era para as atividades ocupacionais. No ano de 1984, 27 alunos maiores de 16 anos eram atendidos na profissionalização, com base essencialmente ocupacional, envolvendo afazeres artesanais (FEDERAÇÃO NACIONAL DAS APAES, 2005, p. 201).

Na década de 1980, a APAE de Toledo começou a se relacionar com outras instituições e passou a organizar eventos envolvendo as outras APAES do Paraná e do Brasil. Dentre os eventos podemos destacar: o XV Encontro Estadual das APAES do Paraná, que teve como finalidade discutir as temáticas da educação especial e reunir os profissionais das escolas especiais do Paraná (APAE de TOLEDO - Livro Ata, 1980. p. 29), e as Olimpíadas Estaduais das APAES do Paraná em 1988, com a participação de vários municípios e mais de 800 atletas (APAE de TOLEDO - Livro Ata, 1988, p. 54).

No final do ano de 1993, com o crescimento no número de alunos adultos e a necessidade de compor o setor profissionalizante na escola, a APAE adquiriu dois alqueires e meio de terra, localizados no interior do município de Toledo. Essas terras foram adquiridas, tendo em vista a falta de espaço para ampliação das atividades na instituição, principalmente para as Oficinas Protegidas e as Oficinas Profissionalizantes que faziam parte da educação profissional (APAE de TOLEDO - Livro Ata, 1993, p. 57).

Em setembro de 1996, a APAE de Toledo instalou o Setor Profissionalizante ${ }^{12}$ nas terras adquiridas em 1993. A APAE Agrícola ${ }^{13}$ da Escola Especial Bem Me Quer entraria, portanto, em pleno funcionamento. Possuía $948 \mathrm{~m}^{2}$ de área construída e dois alqueires de área livre, mantida pela APAE de Toledo. O projeto da construção foi chamado de Projeto Poty. Poty é nome da localidade do interior onde a área de terra foi comprada. Conforme mencionamos, o principal objetivo foi a instalação de Oficinas Protegidas e Oficinas Profissionalizantes para compor os programas da Educação Profissional, contemplando espaços para as atividades de tapeçaria e marcenaria, bem como a infra-estrutura adequada para o pomar, horta, minhocário, criação de gado e estufa para flores (APAE de TOLEDO - Livro Ata, 1996, p. 60).

As Oficinas Protegidas foram predominantes nas instituições especializadas até os anos 1990 e constituíam uma ação extensiva à Educação Especial. Com o processo de reformas socioeconômicas, políticas e culturais introduzidas com as mudanças que ocorreram na esfera da produção capitalista, novas perspectivas e demandas foram conferidas para Educação Profissional, visando ultrapassar os treinamentos repetitivos realizados nas Oficinas Protegidas.

Assim sendo, a partir da década de 1990, os programas de Educação Profissional para a pessoa com deficiência, ao estarem inseridas na dinâmica do processo de reestruturação produtiva refletiram, em certa medida, as competências e habilidades

Revista HISTEDBR On-line, Campinas, número especial, p. 100-110, mai2012 - ISSN: 1676-2584 102 
básicas exigidas para o trabalhador na referida década. A formação, nesse contexto, estaria voltada para a competitividade, ou seja, as pessoas com deficiência disputariam "em situação de igualdade, postos de trabalho ocupados por outros trabalhadores" (FEDERAÇÃO NACIONAL DAS APAES, 2007, p. 118), perspectiva que também se expressou no PPP da APAE de Toledo - PR, ao considerar a aquisição de "competências e habilidades para enfrentar o processo produtivo, o trabalho em equipe e a competição cada vez mais acirrada pelo emprego" (APAE DE TOLEDO, Projeto Político-Pedagógico, 2009, p. 111).

É dessa forma que na década de 1990 a Educação Profissional foi reestruturada a partir do discurso da valorização da qualificação, com a inclusão de "serviços e programas no campo da Educação Profissional, para iniciar, qualificar e incluir a pessoa com deficiência no mercado de trabalho" (FEDERAÇÃO NACIONAL DAS APAES, 1997, p. 09). Seguindo as orientações da FENAPAES, as APAES do Brasil, a partir de 1998, implantaram o Processo de Educação Profissional e Colocação no Trabalho (PECT), visando oferecer diversos programas para a profissionalização da pessoa com deficiência.

É no ano de 1998, portanto, que a APAE de Toledo reorganiza o Setor Profissionalizante $^{14}$, a partir do Processo de Educação Profissional e Colocação no Trabalho (PECT), baseado no livro Educação Profissional e Colocação no Trabalho: uma nova proposta de trabalho junto à pessoa portadora de deficiência - Um manual para profissionais e dirigentes, elaborado pela FENAPAES e publicado em 1997. A partir de então a APAE de Toledo implantou na Educação Profissional os programas de Iniciação Profissional, Qualificação Profissional e Colocação no Trabalho (APAE de TOLEDO, Livro Ata, 1998, p. 61).

O livro Educação Profissional e Colocação no Trabalho: uma nova proposta de trabalho junto à pessoa portadora de deficiência - Um manual para profissionais $e$ dirigentes foi, realmente, um divisor de águas para as instituições que trabalhavam com as pessoas deficientes, como é o caso da APAE de Toledo, nosso objeto de estudo.

O livro foi uma das primeiras publicações a difundir o conceito de inclusão aplicado a um processo capaz de garantir sucesso no mercado de trabalho para as pessoas com deficiência mental. Nos programas tradicionais, a idéia central era a de modificar as pessoas com deficiência a fim de torná-las aceitáveis ao mercado de trabalho formado com base no hoje questionável perfil de "pessoa normal". Pelo paradigma da inclusão, é o mercado de trabalho que deve adequar suas estruturas humanas, físicas e técnicas às pessoas com deficiência (SASSAKI, 2003, p. 112)

Nesse sentido, a APAE de Toledo, como a maioria das instituições mantidas pela FENAPAES no Brasil, passou por um processo de desenvolvimento da Educação Profissional. Desde a sua fundação, até o ano de 1998, a Educação Profissional tinha um caráter terapêutico ${ }^{15}$. "A maioria dos programas implantados, apesar de serem denominados de profissionalização, possuía muito mais o intuito terapêutico do que a profissionalização propriamente dita" (BATISTA, 2003, p. 59).

A Educação Profissional da APAE de Toledo ${ }^{16}$ está organizada a partir dos Programas de Iniciação Profissional, Qualificação Profissional e Colocação no Mundo do Trabalho, que compõem o Processo de Educação Profissional e Colocação no Trabalho (PECT) iniciado em 1998. Os programas integram a proposta do Projeto PolíticoPedagógico $^{17}$ da instituição, mas para cada uma de suas etapas, existe um currículo Revista HISTEDBR On-line, Campinas, número especial, p. 100-110, mai2012 - ISSN: 1676-2584 103 
próprio, compreendendo objetivos, conteúdos programáticos, metodologias e processo de avaliação (APAE DE TOLEDO - Projeto Político-Pedagógico, 2009, p. 44).

A Educação Especial ofertada pela APAE de Toledo tem os seguintes objetivos:

1. Oferecer ao educando com deficiência intelectual e múltiplas de altas especificidades, condições adequadas de aprendizagem através de um processo educacional, que atenda as suas necessidades e promova o desenvolvimento de seu potencial respeitada suas limitações; 2. Garantir o direito à educação básica formal, nos níveis de ensino da Educação Infantil, Ensino Fundamental/anos iniciais e Educação Profissional/inicial aos educandos com deficiência intelectual e múltiplas de alta especificidade conforme determina a Resolução 3.616/2008 da Secretaria de Estado da Educação; 3. Elaborar coletivamente seu Projeto PolíticoPedagógico na perspectiva de uma educação inclusiva com observância aos princípios democráticos e submetidos à aprovação da Entidade Mantenedora e do Conselho Escolar e homologado pelo Núcleo Regional de Educação; 4. Assegurar aos educandos currículo, métodos, técnicas, recursos educativos, avaliação que atenda suas necessidades e possibilidades; 5. Oportunizar o aperfeiçoamento constante dos profissionais visando a melhoria de qualidade de ensino no ambiente escolar; 6. Criar espaços de participação e responsabilidade da família no processo escolar (APAE DE TOLEDO - Projeto Político-Pedagógico, 2009, p. 31).

Para o ingresso do aluno ${ }^{18}$ na APAE de Toledo, a equipe multidisciplinar formada por profissionais da escola (pedagogo, psicólogo e assistente social) realiza a Avaliação Inicial - Diagnóstica. Os alunos são reavaliados, anualmente, pelo professor regente da turma, juntamente com a equipe multidisciplinar para verificar a possibilidade de encaminhamento para o ensino regular. $\mathrm{Na}$ impossibilidade dessa inserção, o aluno continua estudando na instituição e, ao completar 16 anos é inserido nos Programas de Educação Profissional (APAE DE TOLEDO - Projeto Político-Pedagógico, 2009, p. 47).

A APAE de Toledo objetiva garantir aos dispositivos da Constituição Federal de 1988 e suas bases legais de âmbito nacional são: Lei $n^{\circ}$. 7.853/1989 que dispõe sobre a Política Nacional para a Integração da Pessoa portadora de Deficiência; Lei n 9.394/1996 (LDB), Decretos Federais no 2.208/1997 e no 3.298/1999, Lei no 8.859/1994 que garante o estágio para as pessoas com deficiência e a Resolução do Conselho Nacional de Educação de 2001, que instituiu as Diretrizes Nacionais para a Educação Especial (APAE DE TOLEDO - Projeto Político-Pedagógico, 2009, p. 30).

Com o apoio dessa legislação, abrem-se para as pessoas com deficiência mental e múltipla diferentes portas de acesso e permanência no trabalho $^{19}$, incluindo formas alternativas que favorecem tanto as pessoas com comprometimentos leves, que podem ascender ao diversificado e restrito mercado tradicional de trabalho, quanto as pessoas que, devido a comprometimento mais severos, necessitam de apoio permanente na sua prática profissional (OLIVEIRA, 2003, p. 157).

Na APAE de Toledo, o professor de cada programa e a equipe multidisciplinar (pedagogo, psicólogo e assistente social), que respondem pelos Programas de Educação Profissional que compõem o PECT, são responsáveis por identificar os interesses e as 
potencialidades dos alunos, visando o encaminhamento para os Programas e também garantir as condições de empregabilidade.

A Educação Profissional da pessoa com deficiência compreende todas as etapas do $\mathrm{PECT}^{20}$, visando a terminalidade específica ${ }^{21}$, que seria a inclusão do aluno em algum programa profissionalizante fora da escola (como os cursos do sistema $\mathrm{S})^{22}$ ou a inserção do aluno no mercado de trabalho (APAE EDUCADORA, 2001, p. 31).

Em relação à terminalidade,

Quando os alunos com necessidades educacionais especiais, ainda que com os apoios e adaptações necessários, não alcançarem os resultados de escolarização previstos no Artigo 32, inciso I da LDB 9.394/1996: “o desenvolvimento da capacidade de aprender, tendo como meios básicos o pleno domínio da leitura, da escrita e do cálculo" - e uma vez esgotadas as possibilidades apontadas nos Artigos 24, 26 e 32 da LDB - as escolas devem fornecer-lhes uma certificação de conclusão de escolaridade, denominada terminalidade específica. Terminalidade específica é uma certificação de conclusão de escolaridade - fundamentada em avaliação pedagógica - com histórico escolar que apresente, de forma descritiva, as habilidades e competências atingidas pelos educandos com grave deficiência mental. É o caso dos alunos cujas necessidades educacionais especiais não lhes possibilitaram alcançar o nível de conhecimento exigido para a conclusão do ensino fundamental, respeitada a legislação existente, e de acordo com o regimento e o projeto pedagógico da escola. $\mathrm{O}$ teor da referida certificação de escolaridade deve possibilitar novas alternativas educacionais, tais como o encaminhamento para cursos de Educação de Jovens e Adultos e de Educação Profissional, bem como a inserção no mundo do trabalho, seja ele competitivo ou protegido ${ }^{23}$ (IÁCONO, 2003, p. 117).

Para a APAE de Toledo, a terminalidade acadêmica, chamada de terminalidade específica, pode ser assim compreendida: a pessoa com deficiência, ao ingressar na escola, é submetida a uma avaliação realizada pela equipe muldidisciplinar (pedagodo, psicólogo e assistente social), conforme mencionamos anteriormente. Posteriormente, durante a permanência na escola, a avaliação será realizada anualmente pela mesma equipe, em conjunto com o professor regente da turma. Se o aluno acompanhar os conteúdos mais específicos referentes a sua idade cronológica, a equipe muldidisciplinar orienta a família para que ele seja matriculado no ensino regular para dar continuidade a sua escolarização. Daí em diante, a terminalidade será dada no ensino regular (APAE DE TOLEDO - Projeto Político-Pedagógico, 2009, p. 49).

Operacionalizado o currículo nas dimensões estabelecidas pela presente proposta, a certificação de conclusão de escolaridade ocorrerá, através da terminalidade específica com característica codificada e/ou descritiva, explicitando as habilidades e competências desenvolvidas pelos educandos portadores de deficiência mental, observando os dispositivos legais vigentes e o regimento da instituição (APAE EDUCADORA, 2001, p. 31).

Conforme afirmamos acima, se em virtude do acentuado grau de sua deficiência o aluno não foi incluído no ensino regular, será mantido na escola e ao completar 16 anos irá 
freqüentar os Programas de Educação Profissional. Após cursar os Programas que compreendem as três etapas do PECT e estiver apto para o trabalho, o aluno terá alcançado o fim do seu processo de estudo e profissionalização na APAE, sendo encaminhado para o mercado de trabalho. Como a APAE de Toledo não trabalha com o sistema de notas (boletim), a certificação do aluno ocorre por meio de um relatório, cuja descrição compreende as diversas disciplinas ou áreas da grade curricular. O relatório é entregue em uma solenidade de formatura para os pais. Os alunos empregados ficam desvinculados da instituição (APAE DE TOLEDO - Projeto Político-Pedagógico, 2009, p. 50).

No momento em que os alunos são contratados por alguma empresa, a equipe multidisciplinar acompanha-os por um período de até dois anos. São promovidos, por meio de autorização da empresa, encontros, palestras e troca de experiências entre os alunos incluídos no mercado e os que estão nos Programas de Educação Profissional da APAE, com exceção dos alunos matriculados nas Oficinas Protegidas. Essa interlocução ocorre por meio do projeto "Revisitando a inclusão no mercado de trabalho", cujo "objetivo é verificar o desempenho profissional, relacionamento, participação e nível de satisfação pessoal dos alunos" (APAE DE TOLEDO, 2010, p. 02).

Sustenta-se que os Programas de Educação Profissional da APAE de Toledo devem ser abrangentes, considerando todos os aspectos do desenvolvimento do ser humano: emocionais, cognitivos, físicos, sociais e políticos, os quais visam promover a inclusão efetiva das pessoas com deficiência na sociedade (APAE DE TOLEDO - Projeto PolíticoPedagógico, 2009, p. 111).

A APAE de Toledo também expressa a preocupação com a competitividade do processo produtivo. Assim sendo, defende a habilitação profissional pautada nas competências e habilidades. Essa perspectiva ocorre devido o mercado de trabalho exigir, cada vez mais, que a habilitação profissional seja fundamentada nas competências pessoais da pessoa com deficiência, ou seja, ela precisa adquirir competências e habilidades para enfrentar o processo produtivo, o trabalho em equipe e a competição cada vez mais acirrada pelo emprego (APAE DE TOLEDO - Projeto Político-Pedagógico, 2009, p. 111).

Em síntese, na APAE de Toledo, no ano de 1998, foi reorganizado o Setor Profissionalizante, a partir do Processo de Educação Profissional e Colocação no Trabalho (PECT). A instituição atendeu, desde o ano de 1998, um total de 3.864 alunos. Deste número, 1.632 alunos foram matriculados no Setor Educacional e 2.198 alunos freqüentaram os diferentes programas do PECT e das Oficinas Protegidas Terapêuticas. Entre os anos de 1998 a 2010 foram encaminhados ao mercado de trabalho 34 alunos.

\section{REFERÊNCIAS}

APAE EDUCADORA. A escola que buscamos: proposta orientadora das ações educacionais / coordenação geral : Ivanilde Maria Tíbola. . Brasília : Federação Nacional das APAEs, 2001.

APAE DE TOLEDO - Livro Ata, Toledo - Pr, 1974.

APAE DE TOLEDO - Livro Ata, Toledo - Pr, 1976. 
APAE DE TOLEDO - Livro Ata, Toledo - Pr, 1977.

APAE DE TOLEDO - Livro Ata, Toledo - Pr,, 1979.

APAE DE TOLEDO - Livro Ata, Toledo - Pr, 1980.

APAE DE TOLEDO - Livro Ata, Toledo - Pr, 1988.

APAE DE TOLEDO - Livro Ata, Toledo - Pr, 1993.

APAE DE TOLEDO - Livro Ata, Toledo - Pr, 1996.

APAE DE TOLEDO - Livro Ata, Toledo - Pr, 1998.

APAE DE TOLEDO. Projeto Político-Pedagógico. Toledo - Pr, 2009.

APAE DE TOLEDO. Relatório Anual do PECT. Toledo - Pr, 2010.

BATISTA, Cristina A. Mota. Educação profissional e inclusão no trabalho: entraves e possibilidades. In: Trabalho e deficiência mental: perspectivas atuais. APAE, Dupligráfica editora, Brasília, 2003.

CARVALHO, Rosita Édler de. A nova LDB e a educação especial. Rio de Janeiro: WVA, 1997.

FEDERAÇÃO NACIONAL DAS APAES. Educação profissional e colocação no trabalho: Uma nova proposta de trabalho junto à pessoa portadora de deficiência. Um manual para profissionais e dirigentes. Brasilia, FENAPAES, 1997.

Metodologias aplicadas na educação profissional de pessoas com deficiência mental e múltipla. FENAPAES, Brasilia, 2005.

Educação profissional e trabalho para pessoas com deficiências intelectual e múltipla. Plano orientador para gestores e profissionais. FENAPAES, Brasília, 2007.

IÁCONO, Jane Peruzo. Deficiência mental e terminalidade específica: novas possibilidades de inclusão ou exclusão velada. Maringá - Pr, UEM, 2003. (Dissertação de Mestrado).

NIEDERAUER, Ondy Helio. Toledo no Paraná: a historia de um latifúndio improdutivo, sua reforma agrária, sua colonização, seu progresso. 2 Ed. Toledo, Tolegraf, 2004.

OLIVEIRA, Maria Helena Alcântara de. Trabalho e deficiência mental: Perspectivas atuais. In: Trabalho e deficiência mental: perspectivas atuais. APAE, Dupligráfica editora, Brasília, 2003.

PARANÁ. Decreto Estadual no 3.528 de 02 de junho de 1977. Autoriza o funcionamento da Escola Especial Bem Me Quer. SEED, 1977. 
ROSA, Enio Rodrigues da. O trabalho das pessoas com deficiência e as relações sociais de produção capitalista: uma análise crítica da política de cotas no Brasil. UNIOESTE, Cascavel, PR: [s.n.], 2009. (Dissertação de Mestrado).

SASSAKI, Romeu Kazumi. Educação profissional e emprego de pessoas com deficiência mental pelo paradigma da inclusão. In: Trabalho e deficiência mental: perspectivas atuais. APAE, Dupligráfica editora, Brasília, 2003.

SILVA, Oscar. Toledo e sua história. Toledo, Prefeitura Municipal, 1998.

TOLEDO 50 ANOS. Cinco décadas de histórias. Toledo, Sul Gráfica Editora, 2002.

\section{Sites na Internet consultados:}

www.ibge.gov.br/cidadesat/painel/painel.php?codmun=412770

Notas

${ }^{1}$ Graduada em Pedagogia (UNIOESTE). Mestre e Doutora em Educação (UNICAMP). Professora do Colegiado do Curso de Pedagogia e do Mestrado em Educação da UNIOESTE - Universidade Estadual do Oeste do Paraná - Campus de Cascavel - PR. Pesquisadora do Grupo de Estudos e Pesquisas em Política Educacional e Social - GEPPES/UNIOESTE.

${ }^{2}$ Graduado em Filosofia (UNIOESTE). Mestre em Educação pelo Programa de Pós-Graduação em educação da UNIOESTE - Universidade Estadual do Oeste do Paraná - Campus de Cascavel - PR. Docente da Escola Especial Bem Me Quer - APAE de Toledo - PR. Docente do Colegiado de Pedagogia da Faculdade Sul Brasil (FASUL), Toledo - Paraná.

${ }^{3}$ O Município de Toledo está situado na região Oeste do Estado do Paraná, tendo área total de 209 mil metros quadrados. Sua colonização teve início no ano de 1940, quando um grupo de empresários do Rio Grande do Sul resolveu adquirir uma extensa área de 274.846 hectares de mata virgem, com uma fronteira ribeirinha de $43 \mathrm{~km}$ de terras ao longo do Rio Paraná, desde a foz do rio Guaçú até a foz do rio São Francisco Falso, e $78 \mathrm{Km}$ de Oeste a Leste, formando um enorme retângulo contendo mata nativa e uma diversa fauna, território esse que pertencia ao município de Foz do Iguaçu (SILVA, 1998, p. 58). Segundo dados do Censo de 2010, a cidade conta com aproximadamente 119.313 mil habitantes Disponível em: (www.ibge.gov.br/cidadesat/painel/painel.php?codmun=412770).

4 A Colonizadora Maripá S/A foi a empresa gaúcha responsável por adquirir e revender as terras que formavam a Fazenda Britânia. Essas terras se transformaram, mais tarde, no município de Toledo (TOLEDO 50 ANOS, 2002, p. 128).

${ }^{5}$ A primeira escola oficial foi denominada de Grupo Escolar Luiz Augusto Moraes Rego. Em relação as instituições religiosas, destacam-se os anos de 1948 e 1955. Assim sendo, em 1948, chegaram ao município as Irmãs de São Vicente de Paulo, sendo criado o Instituto Imaculado Coração de Maria, chamado posteriormente de INCOMAR (SILVA, 1998, p. 126). Em outubro de 1955, a Congregação dos Irmãos Lassalistas iniciaram as suas atividades escolares (NIEDERAUER, 2004, p. 250). A respeito da história das instituições escolares no município conferir, dentre outros, (SILVA, 1998; NIEDERAUER, 2004).

${ }^{6}$ A primeira reunião feita para oficializar a instalação da entidade foi realizada em 30 de maio de $1973 \mathrm{em}$ uma sala situada no Edifício Atlas, na Rua 14 de julho, centro. Depois de muitas discussões, esse grupo de pais e pessoas interessadas na questão tiveram os subsídios necessários para criar uma entidade filantrópica, sem fins lucrativos, filiada a Federação Nacional das APAES, para ofertar atendimento social, cultural e educacional para as pessoas com deficiência intelectual (APAE de TOLEDO - Livro Ata, 1974, p. 7).

Revista HISTEDBR On-line, Campinas, número especial, p. 100-110, mai2012 - ISSN: 1676-2584 108 
${ }^{7}$ A primeira diretoria da APAE de Toledo foi assim constituída: Presidente: Adolfo Dall Oglio; VicePresidente: Gilberto Alves Branco; Primeiro Secretário: Heleno Scherer; Segundo Secretário: Luis Jorge Kracher; Primeiro Tesoureiro: Severino Jambersi; Segundo Tesoureiro: Alcides Nardi (APAE de TOLEDO Livro Ata, 1974, p. 8).

${ }^{8}$ As atividades da Escola Especial, nominada como Escola da APAE, funcionou num prédio cedido pelo senhor Adolfo Dall Oglio e sua esposa Vênus Dall Oglio, com localização no centro de Toledo, na Rua Sarandi, $\mathrm{n}^{\circ}$ 173. O prédio de madeira continha 4 salas de aula, 1 cozinha, 1 banheiro e uma pequena área livre. Inicialmente atendeu 09 alunos, os quais foram avaliados pela equipe do Departamento de Educação Especial do Estado, com diagnóstico de deficientes treináveis. (APAE de TOLEDO - Livro Ata, 1976, p. 9).

${ }^{9}$ Os primeiros profissionais foram a professora Maria Helena Andrade como diretora, Maria Helena Garicoix e Maria Helena Vegas como professoras e Mirian dos Santos como servente (APAE de TOLEDO - Livro Ata, 1977, p. 11).

${ }^{10}$ Com o crescente número de matrículas na escola, a diretoria da entidade começou a pressionar o poder público para obter recursos para a compra de um terreno e a construção da sede própria da entidade. Assim, na reunião do dia 14 de junho de 1978, o projeto e a planta da nova escola foi apresentado pelo Dr. Darlan Muraro a toda a diretoria da entidade, iniciando, assim, as campanhas para angariar os recursos necessários. No dia 06 de maio de 1979, foi feito o lançamento oficial da Pedra Fundamental da nova escola, com a presença do então Governador do Estado do Paraná Nei Braga (APAE de TOLEDO - Livro Ata, 1979, p. 26).

${ }^{11}$ Situada no centro da cidade, Rua Bonfim, 1621, com $1.900 \mathrm{~m}^{2}$ de área construída e $1.100 \mathrm{~m}^{2}$ de área livre.

${ }^{12}$ Os alunos maiores de 16 anos passaram a estudar, em tempo integral, no Setor Profissionalizante da APAE Agrícola, sendo um grupo de professores e funcionários encaminhados para a referida extensão, já que o Setor Profissionalizante funcionava num espaço junto com as demais crianças na escola do centro (APAE DE TOLEDO - Livro Ata, 1996, p. 60).

${ }^{13}$ Denominação dada pela comunidade que ainda permanece.

${ }^{14}$ No ano de 1998, o Setor Profissionalizante da APAE de Toledo ou a educação profissional, tanto da APAE do centro como a da APAE agrícola, bem como as oficinas protegidas terapêuticas, passaram a fazer parte do Processo de Educação e Colocação no Trabalho (PECT). Mas o termo ainda se confunde. Na maioria dos documentos, para falar do PECT, a APAE usa o termo Educação Profissional. Segundo a Coordenadora pedagógica do PECT, no setor profissionalizante estão todas as etapas do PECT e as oficinas protegidas terapêuticas, tanto na APAE do centro como na APAE agrícola de Toledo.

15 De 1998 até os dias de hoje, esse caráter terapêutico foi sendo substituído pela categoria da empregabilidade. Para Sassaki (2003, p. 117), atualmente esse conceito de empregabilidade vai além da idéia de formação profissional para obtenção de um emprego. Para ele, o novo enfoque da empregabilidade se dá na lógica das competências (conhecimentos, habilidades e atitudes), na funcionalidade e na autonomia. "A empregabilidade não resulta apenas do esforço individual da pessoa com deficiência, que procuraria ser mais qualificada através de cursos de capacitação profissional. A empregabilidade dessa pessoa depende também de uma nova postura por parte de outras pessoas à sua volta: familiares, potenciais empregadores, instrutores de escolas profissionalizantes e assim por diante" (SASSAKI, 2003, p. 118).

${ }^{16}$ Importante ressaltar que a Educação Profissional na APAE de Toledo não corresponde a um curso técnico vinculado ao sistema S (SESI, SENAI, SENAC, etc.) ou a outra instituição ou escola técnica capaz de conceder aos alunos uma certificação profissional. Todavia, ao concluir a etapa de Educação Profissional o aluno pode ser incluído em um curso do sistema $S$ ou a qualquer outra agência formadora para obter um registro ou um diploma, desde que ele seja apto para o ingresso, ou seja, alcançou uma escolaridade mínima exigida, no caso, se alfabetizou. Mas, na APAE de Toledo não há registro dessa inserção, pois o aluno que tem capacidade mínima para os conteúdos acadêmicos (do ensino fundamental, por exemplo) é incluído no ensino regular e desvinculado da APAE antes de completar 16 anos. No entanto, para 2011 existe a possibilidade de realização de uma parceria entre a APAE e o SENAI de Toledo, conforme o Ofício n ${ }^{\circ} 01$, de 23 de novembro de 2010, enviado pela diretora da APAE ao diretor do SENAI de Toledo. O objetivo é

Revista HISTEDBR On-line, Campinas, número especial, p. 100-110, mai2012 - ISSN: 1676-2584 109 
proporcionar aos alunos um curso em uma área oferecida pelo SENAI, visando a certificação ao concluí-lo. Destaca-se, por exemplo, a oferta pelo SENAI do curso de operador de máquina de costura industrial. Alguns alunos da APAE que já freqüentaram o programa de qualificação/habilitação profissional poderão ser matriculados nesse curso. Caso concluírem, obterão a certificação exigida para a possível contratação nas empresas de costura da cidade.

${ }^{17}$ No ano de 2001, a Federação Nacional das APAES lançou um documento denominado "Projeto PolíticoPedagógico: subsídios orientadores", o qual visava orientar as APAES brasileiras na construção dos seus respectivos Projetos Político-Pedagógicos, garantindo os dispositivos contemplados na Constituição Federal de 1988 e na Lei de Diretrizes e Bases da Educação Nacional 9.394/1996. O objetivo foi o de estabelecer os parâmetros nacionais comuns para todas as APAES do Brasil, no que se refere a educação da pessoa com deficiência. A APAE de Toledo fez várias reuniões com os professores e com a equipe pedagógica da escola para elaborar o projeto seguindo as orientações da federação, bem como, estudou os textos de Ilma Passos A. Veiga e Antonio Joaquim Severino. Assim sendo, até o ano de 2001, a APAE de Toledo tinha o Projeto Político-Pedagógico, o Estatuto e o Regimento interno próprio. O que ocorreu depois de 2001, é que o PPP foi padronizado, seguindo a estrutura recomendada pela FENAPAES. Porém, o processo de reelaboração do PPP demandou um determinado tempo. Do ano de 2003 até 2008 o PPP sofreu adequações no seu conteúdo. Para a elaboração dessa dissertação, tomamos como referência o PPP de 2008, o qual foi aprovado pela Secretaria de Estado de Educação (SEED) e pelo Departamento de Educação Especial, em 2009.

${ }^{18}$ Esses alunos podem ser crianças de 0 a 10 anos, adolescentes até os 16 anos ou adultos.

${ }^{19}$ Sobre os desafios/dificuldades da inserção dos indivíduos no mercado de trabalho consultar, dentre outros, Enio Rodrigues da Rosa (2009); Romeu Kazumi Sassaki (2003); Cristina Abranches Mota Batista (2003).

${ }^{20} \mathrm{Na}$ APAE de Toledo, o PECT, portanto, é desenvolvido a partir de três etapas: A $1^{\mathrm{a}}$ Etapa, Iniciação para o Trabalho, está divida em dois programas: Avaliação inicial para o trabalho e Iniciação Profissional. A $2^{\text {a }}$ Etapa, Qualificação/Habilitação Profissional, contempla os Programas de Treinamento Profissional e

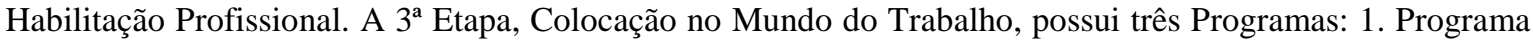
Emprego competitivo aberto (tradicional); 2. Programa Emprego competitivo apoiado (apoiado individual); e 3. Programa Trabalho autônomo (individual e cooperativa).

${ }^{21}$ Para aprofundar a controversa questão da terminalidade específica e da temporalidade, podemos consultar, entre outros: Rosita Edler de Carvalho (1997) e Jane Peruzzo Iácono (2003).

${ }^{22}$ Conforme mencionamos, essa possibilidade está sendo prevista, conforme Ofício $\mathrm{n}^{\circ} 01$, de 23 de novembro de 2010, enviado pela diretora da APAE ao diretor do SENAI de Toledo.

${ }^{23}$ Trabalho protegido ou apoiado é uma alternativa de inserção profissional de todas as categorias de deficiencias com maior comprometimento. Favorece aqueles que apresentam impedimentos, pela natureza e intensidade de suas limitações, de ser inserido no mercado de trabalho competitivo. Essa inserção profissional protegida terá apoio constante de um instrutor/ajudante (FEDERAÇÃO NACIONAL DAS APAES, 2007, p. 125).

Recebido em: $\quad 21.04 .12$

Aprovado em: $\quad 30.05 .12$ 